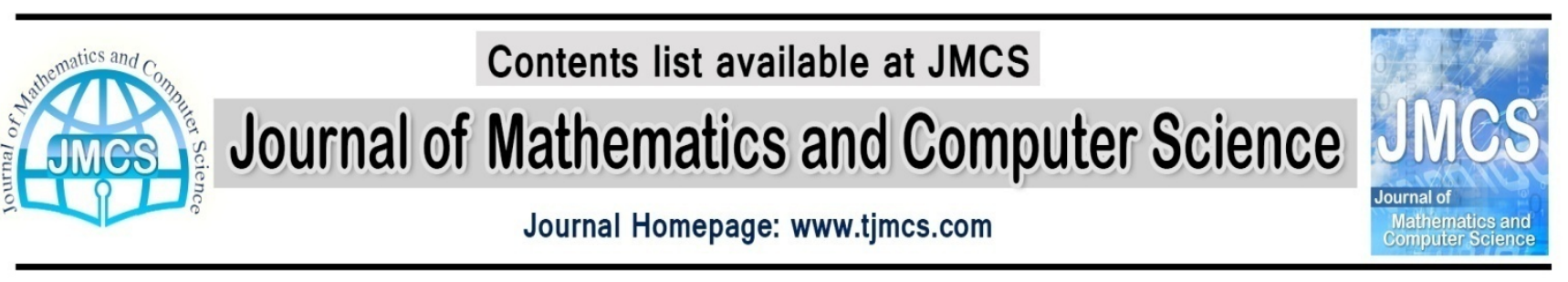

\title{
Common Fixed Point Theorem for Expansive Mappings in G-Metric Spaces
}

\author{
R. K. Vats ${ }^{1}$, S. Kumar ${ }^{2}$, V. Sihag ${ }^{1}$ \\ ${ }^{1}$ National Institute of Technology, Hamirpur (H.P.)-177005 \\ ${ }^{2}$ DCR University of Science and Techonology Murthal, Sonepat (Haryana) \\ E-mail: ramesh_vats@rediffmail.com(Vats), sanjaymudgal2004@yahoo.com(Kumar), \\ vsihag3@gmail.com(Sihag)
}

Article history:

Received March 2012

Accepted December 2012

Available online January 2013

\begin{abstract}
In this paper, we introduce the concept of compatible and compatible mapping of type (A) in G-metric space akin to compatible and its type (A) in metric space introduced by Jungck [7] and Jungck et.al [8] and then establishes an example to show their independency. Further, we prove a common fixed point theorem for two pair of expansive mappings which generalize and unify the results of Wang et.al. [19] and Daffer et.al. [17]. Examples are given to support the generality of our result. Finally, we elaborate our theorem as an application in product space.

Keywords: G-metric space, fixed point, compatible mapping of type (A) and $\phi$ function of contractive modulus.

\section{Introduction}

In 1984, Dhage [3] introduced the concept of D-metric space. The situation for a D-metric space is quite different from 2-metric spaces. Geometrically, a D-metric $\mathrm{D}(\mathrm{x}, \mathrm{y}, \mathrm{z})$ represent the perimeter of the triangle with vertices $\mathrm{x}, \mathrm{y}$ and $\mathrm{z}$ in $\mathrm{R}^{2}$. Recently, Mustafa and Sims[10] shows that most of the results concerning Dhage's D-metric spaces are invalid. Therefore, they introduced a improved version of the generalized metric space structure, which they called it as G-metric spaces. For more details on G-metric spaces, one can refer to the papers [10]-[13].
\end{abstract}

Now, we give preliminaries and basic definitions which are used throughout the paper.

In 2004, Mustafa and Sims [11] introduced the concept of G-metric spaces as follows: 
Definition 1.1[11] Let $\mathrm{X}$ be a nonempty set, and let $\mathrm{G}: \mathrm{X} \times \mathrm{X} \times \mathrm{X} \rightarrow \mathrm{R}^{+}$be a function satisfying the following axioms:

$\left(G_{1}\right) G(x, y, z)=0$ if $x=y=z$,

$\left(G_{2}\right) 0<G(x, x, y)$, for all $x, y \in X$ with $x \neq y$,

$\left(G_{3}\right) G(x, x, y) \leq G(x, y, z)$, for all $x, y, z \in X$ with $z \neq y$,

$\left(G_{4}\right) G(x, y, z)=G(x, z, y)=G(y, z, x)=\ldots$ (symmetry in all three variables),

$\left(G_{5}\right) G(x, y, z) \leq G(x, a, a)+G(a, y, z)$ for all $x, y, z, a \in X$, (rectangle inequality)

then the function $\mathrm{G}$ is called a generalized metric, or, more specifically a G-metric on $\mathrm{X}$ and the pair (X, $\mathrm{G}$ ) is called a G-metric space.

Definition 1.2[11] Let (X, G) be a G-metric space and let $\left\{x_{n}\right\}$ a sequence of points in $X$, a point $x$ in $X$ is said to be the limit of the sequence $\left\{x_{n}\right\}$, if $\lim _{m, n \rightarrow \infty} G\left(x, x_{n}, x_{m}\right)=0$, and one says that sequence $\left\{x_{n}\right\}$ is $G$ convergent to $\mathrm{x}$.

Thus, that if $x_{n} \rightarrow x$ or $\lim _{n \rightarrow \infty} x_{n}=x$ in a G-metric space (X, G), then if for each $\varepsilon>0$, there exists a positive integer $N$ such that $G\left(x, x_{n}, x_{m}\right)<\varepsilon$ for all $m, n \geq N$.

Now we state some results from the papers ([1], [10]-[13]), which are helpful for proving our main results.

Proposition 1.1[11] Let (X, G) be a G-metric space. Then the following are equivalent:

(i) $\left\{x_{n}\right\}$ is $G$ convergent to $x$,

(ii) $\mathrm{G}\left(\mathrm{x}_{\mathrm{n}}, \mathrm{x}_{\mathrm{n}}, \mathrm{x}\right) \rightarrow 0$ as $\mathrm{n} \rightarrow \infty$,

(iii) $\mathrm{G}\left(\mathrm{x}_{\mathrm{n}}, \mathrm{x}, \mathrm{x}\right) \rightarrow 0$ as $\mathrm{n} \rightarrow \infty$,

(iv) $\mathrm{G}\left(\mathrm{x}_{\mathrm{m}}, \mathrm{x}_{\mathrm{n}}, \mathrm{x}\right) \rightarrow 0$ as $\mathrm{m}, \mathrm{n} \rightarrow \infty$.

Definition 1.3[13] If $(X, G)$ and $\left(X_{1}, G_{1}\right)$ be two G-metric spaces and let $f:(X, G) \rightarrow\left(X_{1}, G_{1}\right)$ be a function, then $\mathrm{f}$ is said to be G-continuous at a point $\mathrm{x}_{0} \in \mathrm{X}$ if given $\varepsilon>0$, there exists $\delta>0$, such that for $\mathrm{x}, \mathrm{y} \in \mathrm{X}$ and $\mathrm{G}\left(\mathrm{x}_{0}, \mathrm{x}, \mathrm{y}\right)<\delta$ implies $\mathrm{G}_{1}\left(\mathrm{f}\left(\mathrm{x}_{0}\right), \mathrm{f}(\mathrm{x}), \mathrm{f}(\mathrm{y})\right)<\varepsilon$. A function $\mathrm{f}$ is $\mathrm{G}$-continuous at $\mathrm{X}$ if and only if it is $\mathrm{G}$-continuous at all $\mathrm{x}_{0} \in \mathrm{X}$ or function $\mathrm{f}$ is said to be G-continuous at a point $\mathrm{x}_{0} \in \mathrm{X}$ if and only if it is G-sequentially continuous at $x_{0}$, that is, whenever $\left\{x_{n}\right\}$ is G-convergent to $x_{0},\left\{f\left(x_{n}\right)\right\}$ is G-convergent to $\mathrm{f}\left(\mathrm{x}_{0}\right)$.

Definition 1.4[11] Let (X, G) be a G-metric space. A sequence $\left\{x_{n}\right\}$ is called G-Cauchy if, for each $\varepsilon>0$, there exists a positive integer $\mathrm{N}$ such that $\mathrm{G}\left(\mathrm{x}_{\mathrm{n}}, \mathrm{x}_{\mathrm{m}}, \mathrm{x}_{l}\right)<\varepsilon$ for all $\mathrm{n}, \mathrm{m}, l \geq \mathrm{N}$, i.e., if $\mathrm{G}\left(\mathrm{x}_{\mathrm{n}}, \mathrm{x}_{\mathrm{m}}, \mathrm{x}_{l}\right) \rightarrow 0$ as $\mathrm{n}$, $\mathrm{m}, l \rightarrow \infty$.

Proposition 1.2[11] If $(\mathrm{X}, \mathrm{G})$ is a $\mathrm{G}$-metric space then the following are equivalent:

(i) The sequence $\left\{x_{n}\right\}$ is G-Cauchy, 
(ii) For each $\varepsilon>0$, there exist a positive integer $N$ such that $G\left(x_{n}, x_{m}, x_{l}\right)<\varepsilon$ for all $n, m, l \geq N$.

Proposition 1.3[11] Let (X, G) be a G-metric space. Then the function G(x, y, z) is jointly continuous in all three of its variables.

Definition 1.5[11] A G-metric space (X, G) is called a symmetric G-metric space if

$$
G(x, y, y)=G(y, x, x) \text { for all } x, y \text { in } X \text {. }
$$

Proposition 1.4[11] Every G-metric space (X, G) will defines a metric space $\left(X, d_{G}\right)$ by

(i) $d_{G}(x, y)=G(x, y, y)+G(y, x, x)$ for all $x, y$ in $X$.

If $(\mathrm{X}, \mathrm{G})$ is a symmetric $\mathrm{G}$-metric space, then

(ii) $d_{G}(x, y)=2 G(x, y, y)$ for all $x, y$ in $X$.

However, if $(X, G)$ is not symmetric, then it follows from the G-metric properties that

(iii) $3 / 2 G(x, y, y) \leq d_{G}(x, y) \leq 3 G(x, y, y)$ for all $x, y$ in $X$.

Definition 1.6[12] A G-metric space (X, G) is said to be G-complete if every G-Cauchy sequence in (X, $\mathrm{G})$ is G-convergent in X.

Proposition 1.5[13] A G-metric space (X, G) is G-complete if and only if (X, $\left.\mathrm{d}_{G}\right)$ is a complete metric space.

Proposition 1.6[12] Let (X, G) be a G-metric space. Then, for any x, y, z, a in X it follows that:

(i) If $G(x, y, z)=0$, then $x=y=z$,

(ii) $G(x, y, z) \leq G(x, x, y)+G(x, x, z)$,

(iii) $G(x, y, y) \leq 2 G(y, x, x)$,

(iv) $\mathrm{G}(\mathrm{x}, \mathrm{y}, \mathrm{z}) \leq \mathrm{G}(\mathrm{x}, \mathrm{a}, \mathrm{z})+\mathrm{G}(\mathrm{a}, \mathrm{y}, \mathrm{z})$,

(v) $G(x, y, z) \leq 2 / 3(G(x, y, a)+G(x, a, z)+G(a, y, z))$,

(vi) $G(x, y, z) \leq(G(x, a, a)+G(y, a, a)+G(z, a, a))$.

\section{Compatible mapping and compatible mapping of type (A)}

There has been a considerable interest to study common fixed point for a pair (or family) of mappings satisfying contractive conditions in metric spaces. Several interesting and elegant results were obtained in this direction by various authors [6, 14 and 18]. In particular, now we look in the context of common fixed point theorem in G-metric spaces.

To prove the existence of common fixed points it is necessary to adopt the following: 
(i) Construction of the sequence $\left\{x_{n}\right\}$

(ii) some mechanism to obtain common fixed point and this problem was overcome by imposing additional hypothesis on a pair of mappings.

Most of the common fixed point theorems have the following steps: (i) Expansion or contraction (ii) continuity of functions (either one or both) and (iii) commuting /minimal commuting or some other condition for pair of mappings were given. In some cases condition (ii) can be relaxed but condition (i) and (iii) are unavoidable.

In last two decades, a major breakthrough was done when in 1986, Jungck [7] proclaimed the new notion what he called "Compatibility of mapping ". This concept has been very useful for obtaining fixed point theorem for pair of mappings satisfying a contractive or expansive type condition and assuming continuity of at least one of mapping.

Self mappings $\mathrm{S}$ and $\mathrm{T}$ of a metric space $(\mathrm{X}, \mathrm{d})$ are said to be compatible if

$$
\begin{aligned}
& \lim _{n \rightarrow \infty} d\left(T S x_{n}, S T x_{n}\right)=0 \text {, whenever }\left\{x_{n}\right\} \text { is a sequence in } X \text { such that } \\
& \lim _{n \rightarrow \infty} S x_{n}=\lim _{n \rightarrow \infty} T x_{n}=t \text {, for some } t \in X \text {. }
\end{aligned}
$$

In 1993, Jungck, Murthy and Cho [8] introduced the concept of compatible mapping of type (A) as follows:

Self mapping $\mathrm{S}$ and $\mathrm{T}$ of a metric space $(\mathrm{X}, \mathrm{d})$ are said to be compatible of type (A) if

$$
\lim _{n \rightarrow \infty} \mathrm{d}\left(\mathrm{TS} x_{n}, \mathrm{SS} x_{n}\right)=0 \text { and } \lim _{n \rightarrow \infty} \mathrm{d}\left(\mathrm{ST} x_{n}, \mathrm{TT} x_{n}\right)=0 \text {, whenever }\left\{x_{n}\right\} \text { is a sequence in } \mathrm{X}
$$
such that $\lim _{n \rightarrow \infty} \mathrm{S} x_{n}=\lim _{n \rightarrow \infty} \mathrm{T} x_{n}=\mathrm{t}$, for some $\mathrm{t} \in \mathrm{X}$.

On the same account, we introduce the concept of compatible mapping and compatible mapping of type (A) in G-metric space, akin to metric space as follows:

Definition 2.1 Self mappings S and T of a G-metric space (X, G) are said to be compatible if

$$
\lim _{n \rightarrow \infty} G\left(T S x_{n}, S T x_{n}, S T x_{n}\right)=0 \text { and } \lim _{n \rightarrow \infty} G\left(S T x_{n}, T S x_{n}, \operatorname{TSx}_{n}\right)=0 \text {, whenever }\left\{x_{n}\right\} \text { is a }
$$
sequence in $X$ such that $S x_{n}=\lim _{n \rightarrow \infty} T x_{n}=t$, for some $t \in X$.

Definition 2.2 Self mappings $S$ and $T$ of a G-metric space $(X, G)$ are said to be compatible mappings of type (A) if

$$
\lim _{n \rightarrow \infty} G\left(\operatorname{TSx}_{n}, \operatorname{SSx}_{n}, S S x_{n}\right)=0 \text { and } \lim _{n \rightarrow \infty} G\left(S T x_{n}, \operatorname{TTx}_{n}, \operatorname{TTx}_{n}\right)=0 \text {, whenever }\left\{x_{n}\right\} \text { is a }
$$
sequence in $X$ such that $\lim _{n \rightarrow \infty} S x_{n}=\lim _{n \rightarrow \infty} T x_{n}=t$, for some $t \in X$.

Lemma 2.1 Let $S$ and $T$ be compatible mappings of type (A) on G-metric space (X, G) into itself and $\lim _{n \rightarrow \infty} S x_{n}=\lim _{n \rightarrow \infty} T x_{n} \rightarrow x$ for some $x$ in $X$, then $\lim _{n \rightarrow \infty} T S x_{n} \rightarrow S x$ if $S$ is sequentially continuous at $x$.

Proof - Suppose that $S$ is sequentially continuous at $x$ and $\lim _{n \rightarrow \infty} S x_{n}=\lim _{n \rightarrow \infty} T x_{n}=x$, then 
$\mathrm{SSx}_{\mathrm{n}} \rightarrow \mathrm{Sx}$ as $\mathrm{n} \rightarrow \infty$. Again, since $\mathrm{S}$ and $\mathrm{T}$ are compatible mappings of type (A), we have $\lim _{n \rightarrow \infty} G\left(T S x_{n}, S S x_{n}, S S x_{n}\right)=0$, i.e., $T S x_{n}=S S x_{n} \rightarrow S x$ as $n \rightarrow \infty$.

Remark 2.1 Compatible mapping and compatible mapping of type (A) are independent as the following example supports:

Example 2.1 Let $X=R$, and $(X, G)$ be a G-metric space defined by $G(x, y, z)=\{|x-y|+|y-z|+\mid z-$ $\mathrm{x} \mid\}$, for all $\mathrm{x}, \mathrm{y}, \mathrm{z}$ in $\mathrm{X}$ and let $\mathrm{S}$, $\mathrm{T}$ be self mapping defined by

$$
S x=x \text {, for all } x \in X \text { and } T x= \begin{cases}0, & \text { if } x \text { is an integer } \\ 1, & \text { if } x \text { is not an integer }\end{cases}
$$

Then for the sequence $\left\{x_{n}\right\}=\left\{1 \pm \frac{1}{n+1}, n \geq 1\right\}$, we have $S x_{n}=S\left(1 \pm \frac{1}{n+1}\right)=1, S x_{n}=1$ as $n \rightarrow \infty$, and $\operatorname{Tx}_{\mathrm{n}}=\operatorname{STx}_{\mathrm{n}}=\mathrm{TSx}_{\mathrm{n}}=1$, but $\operatorname{TTx}_{\mathrm{n}}=0$ as $\mathrm{n} \rightarrow \infty$.

(i) $\lim _{\mathrm{n} \rightarrow \infty} \mathrm{G}\left(\mathrm{STx}_{\mathrm{n}}, \mathrm{TSx}_{\mathrm{n}}, \mathrm{TSx}_{\mathrm{n}}\right)=\mathrm{G}(1,1,1)=0$.

Showing, the pair $(\mathrm{S}, \mathrm{T})$ is compatible.

(ii) $\lim _{n \rightarrow \infty} G\left(S T x_{n}, \operatorname{TTx}_{n}, \operatorname{TTx}_{n}\right)=G(1,0,0)=2 \neq 0$.

Showing, the pair (S, T) is not compatible of type (A).

Following Matkowski [14], let $\Phi$ be set of real functions, $\phi:[0, \infty) \rightarrow[0, \infty)$ satisfying the following conditions:

(i) $\phi$ is non-decreasing and upper semi continuous from right at 0 ,

(ii) $\phi(\mathrm{t})<\mathrm{t}$ for each $\mathrm{t}>0$ and $\phi(\mathrm{t})=0 \Leftrightarrow \mathrm{t}=0$.

Lemma 2.2[14] Let $\phi:[0, \infty) \rightarrow[0, \infty)$ be a function satisfying condition (i) and (ii). Then $\lim _{\mathrm{n} \rightarrow \infty} \phi^{\mathrm{n}}(\mathrm{t})=$ 0 , where $\phi^{\mathrm{n}}(\mathrm{t})$ denote the composition of $\phi(\mathrm{t})$ with $\mathrm{n}$-times.

In 1984, Wang, Li, Gao and Iseki [19] proved fixed point theorems for expansion mappings, which correspond to some contractive mappings in metric spaces.

Daffer and Kaneko [17] proved the following fixed point theorem for a expansive pair of mappings as follows:

Theorem 2.1 Let $(X, d)$ be a complete metric space. Let $S$ be a surjective self map and $T$ be injective self map of $\mathrm{X}$ which satisfy the following conditions:

There exists a number $\mathrm{q}>1$ such that

(2.1) $d(S x, S y) \geq q d(T x, T y)$ for each $x$, $y$ in $X$, then $S$ and $T$ have a unique common fixed point.

Now, we prove our main result which generalizes and unifies the above result in G-metric space by using function defined in lemma 2.2. 


\section{Main results}

Let $\mathrm{A}, \mathrm{B}, \mathrm{S}$ and $\mathrm{T}$ be mapping from a G-metric space (X, G) into itself satisfying the following conditions:

$$
\begin{aligned}
& \text { A and } B \text { are surjective, } \\
& \phi(G(A x, B y, B z)) \geq G(S x, T y, T z)
\end{aligned}
$$

for each $\mathrm{x}, \mathrm{y}, \mathrm{z} \in \mathrm{X}$, where $\phi \in \Phi$. Then for arbitrary point $\mathrm{x}_{0}$ in $\mathrm{X}$, by (3.1), one can choose a point $\mathrm{x}_{1}$ in $\mathrm{X}$ such that $\mathrm{Ax}_{1}=\mathrm{Tx}_{0}=\mathrm{y}_{0}$. For a point $\mathrm{x}_{1}$, there exist a point $\mathrm{X}_{2}$ in $\mathrm{X}$ such that $\mathrm{Bx}_{2}=\mathrm{Sx}_{1}=\mathrm{y}_{1}$. Inductively, one can define a sequence $\left\{\mathrm{y}_{\mathrm{n}}\right\}$ in $\mathrm{X}$ such that

$$
\mathrm{Ax}_{2 \mathrm{n}+1}=\mathrm{Tx}_{2 \mathrm{n}}=\mathrm{y}_{2 \mathrm{n}} \quad: \quad \mathrm{Bx}_{2 \mathrm{n}+2}=\mathrm{Sx}_{2 \mathrm{n}+1}=\mathrm{y}_{2 \mathrm{n}+1}
$$

for all $n \in N$, where $N$ is set of non-negative integers.

First, we establish a Lemma that will be needed to prove our main result as follows:

Lemma 3.1 Let A, B, S and T be mapping of a G-metric space (X, G) into itself satisfying (3.1) and (3.2). Then, the sequence $\left\{y_{n}\right\}$, defined by (3.3) is a G-Cauchy sequence.

Proof - From (3.2), we have

$$
\phi\left(G\left(y_{0}, y_{1}, y_{1}\right)\right)=\phi\left(G\left(A x_{1}, B x_{2}, B x_{2}\right)\right) \geq G\left(S_{1}, T_{2}, T_{2}\right)=G\left(y_{1}, y_{2}, y_{2}\right)
$$

i.e., $\quad \mathrm{G}\left(\mathrm{y}_{1}, \mathrm{y}_{2}, \mathrm{y}_{2}\right) \leq \phi\left(\mathrm{G}\left(\mathrm{y}_{0}, \mathrm{y}_{1}, \mathrm{y}_{1}\right)\right)$.

Similarly, one can show that, $G\left(\mathrm{y}_{2}, \mathrm{y}_{3}, \mathrm{y}_{3}\right) \leq \phi\left(G\left(\mathrm{y}_{1}, \mathrm{y}_{2}, \mathrm{y}_{2}\right)\right) \leq \phi^{2}\left(G\left(\mathrm{y}_{0}, \mathrm{y}_{1}, \mathrm{y}_{1}\right)\right)$.

In general, we get

$$
\mathrm{G}\left(\mathrm{y}_{\mathrm{n}}, \mathrm{y}_{\mathrm{n}+1}, \mathrm{y}_{\mathrm{n}+1}\right) \leq \phi\left(\mathrm{G}\left(\mathrm{y}_{\mathrm{n}-1}, \mathrm{y}_{\mathrm{n}}, \mathrm{y}_{\mathrm{n}}\right)\right) \leq \ldots \ldots \ldots \leq \phi^{\mathrm{n}}\left(\mathrm{G}\left(\mathrm{y}_{0}, \mathrm{y}_{1}, \mathrm{y}_{1}\right)\right) \text {, for all } \mathrm{n} \in \mathrm{N} .
$$

Proceeding to the limit as $n \rightarrow \infty$ and using Lemma 2.2, we have

$$
\lim _{n \rightarrow \infty} G\left(y_{n}, y_{n+1}, y_{n+1}\right)=0 .
$$

Now, by repeated use of $G_{5}$, the rectangular inequality of G-metric space, for every integer $p>0$, we have

$$
G\left(y_{n}, y_{n+p}, y_{n+p}\right) \leq G\left(y_{n}, y_{n+1}, y_{n+1}\right)+G\left(y_{n+1}, y_{n+1}, y_{n+2}\right)+\ldots \ldots+G\left(y_{n+p-1}, y_{n+p}, y_{n+p}\right) .
$$

So, $\lim _{n \rightarrow \infty} G\left(y_{n}, y_{n+p}, y_{n+p}\right)=0$, for every integer $p>0$.

Therefore, $\left\{\mathrm{y}_{\mathrm{n}}\right\}$ is a G-Cauchy sequence.

Using the above lemmas, we prove our main theorem for sequentially continuous mapping. 
Theorem 3.1 Let A, B, S and T be mapping of a complete G-metric space (X, G) into itself satisfying (3.1) and the followings:

(3.4) one of the mappings $\mathrm{A}, \mathrm{B}, \mathrm{S}$ and $\mathrm{T}$ is sequentially continuous,

(3.5) the pair $\{\mathrm{A}, \mathrm{S}\}$ and $\{\mathrm{B}, \mathrm{T}\}$ are compatible mapping of type (A),

if there exist $\phi \in \Phi$ such that inequality (3.2) holds, then A, B, S and T have a unique common fixed point.

Proof - From Lemma (3.1), the sequence $\left\{y_{n}\right\}$ in X defined by (3.3) is G-Cauchy sequence. Since (X, G) is a complete G-metric space, therefore, there exist a point $\mathrm{z}$ in $\mathrm{X}$ such that $\lim _{\mathrm{n} \rightarrow \infty} \mathrm{y}_{\mathrm{n}}=\mathrm{z}$. So $\lim _{\mathrm{n} \rightarrow \infty} \mathrm{Ax}_{2 \mathrm{n}+1}=$ $\mathrm{Tx}_{2 n}=z$ and $\lim _{n \rightarrow \infty} B x_{2 n+2}=\lim _{n \rightarrow \infty} S x_{2 n+1}=z$, i.e., $\lim _{n \rightarrow \infty} A x_{2 n+1}=\lim _{n \rightarrow \infty} \operatorname{Tx}_{2 n}=\lim _{n \rightarrow \infty} B x_{2 n+2}=\lim _{n \rightarrow \infty} S x_{2 n+1}=z$.

First suppose that $A$ is sequentially continuous. So, $\lim _{n \rightarrow \infty} A^{2} x_{2 n+1}=A z$. Since the pair $\{A, S\}$ is compatible mapping of type (A), we obtain from lemma 2.1, $\lim _{n \rightarrow \infty} S A x_{2 n+1}=A z$. By (3.2), we have

$$
\phi\left(G\left(A^{2} x_{2 n+1}, B x_{2 n}, B x_{2 n}\right)\right) \geq G\left(S A x_{2 n+1}, T x_{2 n}, T x_{2 n}\right) .
$$

As $n \rightarrow \infty$, and suppose that $G(A z, z, z) \neq 0$, ones obtain

$$
\mathrm{G}(\mathrm{Az}, \mathrm{z}, \mathrm{z})>\phi(\mathrm{G}(\mathrm{Az}, \mathrm{z}, \mathrm{z})) \geq \mathrm{G}(\mathrm{Az}, \mathrm{z}, \mathrm{z}) .
$$

This contradiction demands that $\mathrm{G}(\mathrm{Az}, \mathrm{z}, \mathrm{z})=0$, implies that $\mathrm{Az}=\mathrm{z}$.

Again by (3.2), we have

$$
\phi\left(G\left(A z, B x_{2 n}, B x_{2 n}\right)\right) \geq G\left(S z, T_{2 n}, T_{2 n}\right) .
$$

Proceeding to the limit $\mathrm{n} \rightarrow \infty$, we get

$$
0=\phi(0)=\phi(G(A z, z, z)) \geq G(S z, z, z) .
$$

which yields that $G(S z, z, z)=0$, i.e., $S z=z$. Now, consider $z=B u$ for some $u \in X$.

Moreover, we have from (3.2)

$$
\phi\left(G\left(A^{2} x_{2 n+1}, B u, B u\right)\right) \geq G\left(S_{2 n+1}, T u, T u\right)
$$

Taking limit as $n \rightarrow \infty$, ones obtain

$$
0=\phi(0)=\phi(\mathrm{G}(\mathrm{Az}, \mathrm{Bu}, \mathrm{Bu})) \geq \mathrm{G}(\mathrm{Az}, \mathrm{Tu}, \mathrm{Tu})
$$

This leads to $G(A z, T u, T u)=0$, implies that $A z=T u$. So, $z=A z=$ Tu. Since the pair $\{B, T\}$ is compatible of type $(\mathrm{A})$ and $\mathrm{z}=\mathrm{Bu}=\mathrm{Tu}$, then $\mathrm{Bz}=\mathrm{BTu}=\mathrm{TTu}=\mathrm{Tz}$. Moreover, we have from (3.2)

$$
\phi\left(G\left(A x_{2 n+1}, B z, B z\right)\right) \geq G\left(S x_{2 n+1}, T z, T z\right) .
$$

Proceeding the limit as $\mathrm{n} \rightarrow \infty$, and suppose that $\mathrm{G}(\mathrm{z}, \mathrm{Tz}, \mathrm{Tz}) \neq 0$, we get 


$$
\mathrm{G}(\mathrm{z}, \mathrm{Tz}, \mathrm{Tz})>\phi(\mathrm{G}(\mathrm{z}, \mathrm{Tz}, \mathrm{Tz})) \geq \mathrm{G}(\mathrm{z}, \mathrm{Tz}, \mathrm{Tz})
$$

This contradiction implies that $\mathrm{G}(\mathrm{z}, \mathrm{Tz}, \mathrm{Tz})=0$. Hence $\mathrm{Tz}=\mathrm{z}$, therefore $\mathrm{z}=\mathrm{Az}=\mathrm{Bz}=\mathrm{Sz}=\mathrm{Tz}$.

Hence $\mathrm{z}$ is common fixed point of $\mathrm{A}, \mathrm{B}, \mathrm{S}$ and $\mathrm{T}$. The proof is similar to the above, if $\mathrm{B}$ is sequentially continuous.

Next suppose that $S$ is sequentially continuous, So, $\lim _{n \rightarrow \infty} S^{2} x_{2 n+1}=S z$. Since the pair $\{A, S\}$ is compatible mapping of type (A), then we have, from lemma (2.1), $\lim _{n \rightarrow \infty} A S x_{n+1}=$ Sz. Now, by using (3.2), we obtain

$$
\phi\left(G\left(A S x_{2 n+1}, B x_{2 n}, B x_{2 n}\right)\right) \geq G\left(S^{2} x_{2 n+1}, T x_{2 n}, T x_{2 n}\right)
$$

Proceeding with the limit $\mathrm{n} \rightarrow \infty$, and suppose that $\mathrm{G}(\mathrm{Sz}, \mathrm{z}, \mathrm{z}) \neq 0$, by using definition of $\phi$ function, we have

$$
\mathrm{G}(\mathrm{Sz}, \mathrm{z}, \mathrm{z})>\phi(\mathrm{G}(\mathrm{Sz}, \mathrm{z}, \mathrm{z})) \geq \mathrm{G}(\mathrm{Sz}, \mathrm{z}, \mathrm{z})
$$

This contradiction leads to $\mathrm{G}(\mathrm{Sz}, \mathrm{z}, \mathrm{z})=0$, implies that $\mathrm{Sz}=\mathrm{z}$. Now, suppose $\mathrm{z}=\mathrm{Av}=\mathrm{Bw}$ for some $\mathrm{v}, \mathrm{w}$ $\in \mathrm{X}$, then by (3.2), ones obtain

$$
\phi\left(G\left(A x_{2 n+1}, B w, B w\right)\right) \geq G\left(S^{2} x_{2 n+1}, T w, T w\right) .
$$

Letting $\mathrm{n} \rightarrow \infty$, we get

$$
0=\phi(0)=\mathrm{G}(\mathrm{z}, \mathrm{Bw}, \mathrm{Bw}) \geq \mathrm{G}(\mathrm{z}, \mathrm{Tw}, \mathrm{Tw})
$$

So, $G(z, T w, T w)=0$, this implies that $T w=z$. Since the pair $\{B, T\}$ is compatible mapping of type (A) and $\mathrm{z}=\mathrm{Bw}=\mathrm{Tw}$, then $\mathrm{Bz}=\mathrm{BTw}=\mathrm{TTw}=\mathrm{Tz}$. Moreover, we find from (3.2) that

$$
\phi\left(G\left(A x_{2 n+1}, B z, B z\right)\right) \geq G\left(S x_{2 n+1}, T z, T z\right) .
$$

Proceeding to the limit $\mathrm{n} \rightarrow \infty$, and suppose that $\mathrm{G}(\mathrm{z}, \mathrm{Bz}, \mathrm{Bz}) \neq 0$, we have

$$
\mathrm{G}(\mathrm{z}, \mathrm{Bz}, \mathrm{Bz})>\phi(\mathrm{G}(\mathrm{z}, \mathrm{Bz}, \mathrm{Bz})) \geq \mathrm{G}(\mathrm{z}, \mathrm{Bz}, \mathrm{Bz}) .
$$

This contradiction implies that $\mathrm{G}(\mathrm{z}, \mathrm{Bz}, \mathrm{Bz})=0$, thus $\mathrm{Bz}=\mathrm{z}$. Hence, $\mathrm{z}=\mathrm{Bz}=\mathrm{Tz}$.

Further, we get

$$
0=\phi(0)=\mathrm{G}(\mathrm{Av}, \mathrm{Bz}, \mathrm{Bz}) \geq \mathrm{G}(\mathrm{Sv}, \mathrm{Tz}, \mathrm{Tz})=\mathrm{G}(\mathrm{Sv}, \mathrm{z}, \mathrm{z})
$$

This gives that $G(S v, z, z)=0$, implies that $S v=z$. Since $\{A, S\}$ is compatible of type $(A)$ and $z=A v=$ $\mathrm{Sv}$, then we have $\mathrm{Az}=\mathrm{ASv}=\mathrm{SSv}=\mathrm{Sz}=\mathrm{z}=\mathrm{Bz}=\mathrm{Tz}$.

Therefore $\mathrm{z}$ is common fixed point of A, B, S and T. Similarly one can complete the proof when $\mathrm{T}$ is sequentially continuous. It follows easily from (3.2) that $\mathrm{z}$ is a unique common fixed point of $\mathrm{A}, \mathrm{B}, \mathrm{S}$ and T.

As a corollary of our theorem we have following: 
Corollary 3.1 Let A, B, S and T be mapping of a G-metric space (X, G) into itself satisfying the condition (3.1), (3.4) and (3.5). Assume that there exist $h>1$ such that

$$
\mathrm{G}(\mathrm{Ax}, \mathrm{By}, \mathrm{Bz}) \geq \mathrm{h} \mathrm{G}(\mathrm{Sx}, \mathrm{Ty}, \mathrm{Tz})
$$

for all $\mathrm{x}, \mathrm{y}, \mathrm{z} \in \mathrm{X}$. Then $\mathrm{A}, \mathrm{B}, \mathrm{S}$ and $\mathrm{T}$ have a unique common fixed point.

Remark 3.1 Theorem 3.1 is more general than corollary 3.1 which is shown by the following example.

Example 3.1 Let $X=\{(\mathrm{u}, \mathrm{v})$ : $\mathrm{u}, \mathrm{v} \in[1, \infty)\}$. Suppose that $(X, \mathrm{G})$ be $\mathrm{G}$-metric space which expresses $\mathrm{G}(\mathrm{x}$, $y, z)$ as perimeter of Euclidean triangle, i.e., $G(x, y, z)=\{|x-y|+|y-z|+|z-x|\}$, with vertices $x=(u$, $v), y=(s, t), z=(p, q)$. We define A, B, S and T: $X \rightarrow X$ by

$$
A(u, v)=\left(u^{2}+1,0\right), B(u, v)=(2,0), S(u, v)=\left(\left(u^{2}+1\right)-\left(u^{2}-1\right)\left(u^{2}+1\right)^{2}, 0\right) \text { and } T(u, v)=(2,0) \text {, }
$$

for all $\mathrm{x} \in \mathrm{X}$. Then it is easily noticed that $A$ and $S$ are compatible of type $(A)$ as $x_{n}=\left(u_{n}, v_{n}\right) \rightarrow(0,1)$. Consider $\phi \in \Phi$ as $\phi(t)=t-\frac{1}{4} t^{3}$ if $t>0$, Further, we see that

$$
\begin{aligned}
\phi(G(A x, B y, B z) & =\phi(G(A(u, v), B(s, t), B(p, q)) \\
& =\phi\left(G\left(\left(u^{2}+1,0\right),(2,0),(2,0)\right)=\phi\left(2\left(u^{2}-1\right)\right)\right. \\
& \left.=2\left(u^{2}-1\right)\left(1-\left(u^{2}-1\right)^{2}\right)\right) \geq 2\left(u^{2}-1\right)\left(1-\left(u^{2}+1\right)^{2}\right)=G(S x, T y, T z),
\end{aligned}
$$

for all $\mathrm{x}, \mathrm{y}, \mathrm{z} \in \mathrm{X}$. Therefore, all the hypothesis of Theorem 3.1 are satisfied.

However, the condition (3.7) is not satisfied. Indeed, for $\mathrm{x}=\left(\frac{1}{2}, 0\right), \mathrm{y}=(0,0)=\mathrm{z}$ and $\mathrm{h}>1$

$$
\begin{aligned}
G(A x, B y, B z) & =G\left(A\left(\frac{1}{2}, 0\right), B(0,0), B(0,0)\right) \\
& =G\left(\left(\frac{5}{4}, 0\right),(2,0),(2,0)\right)=\frac{3}{2} \geq G(S x, T y, T z)=h\left(\frac{155}{64}\right)
\end{aligned}
$$

It is true only when $\mathrm{h} \leq \frac{1}{\mathrm{p}}$, where $\mathrm{p} \geq 2$, which yields a contradiction.

Remark 3.2 The condition of compatibility of type (A) is necessary in Theorem 3.1. To see this we establish the following example.

Example 3.2 Let $X=\{(\mathrm{u}, \mathrm{v})$ : $\mathrm{u}, \mathrm{v} \in[1, \infty)\}$. Suppose that $(\mathrm{X}, \mathrm{G})$ be $\mathrm{G}$-metric space which expresses $\mathrm{G}(\mathrm{x}$, $\mathrm{y}, \mathrm{z})$ as perimeter of Euclidean triangle with vertices $\mathrm{x}=(\mathrm{u}, \mathrm{v}), \mathrm{y}=(\mathrm{s}, \mathrm{t}), \mathrm{z}=(\mathrm{p}, \mathrm{q})$. We define $\mathrm{A}, \mathrm{B}, \mathrm{S}$ and $\mathrm{T}: \mathrm{X} \rightarrow \mathrm{X}$ by

$$
A(u, v)=\left(3 u^{4}+1,0\right) ; B(u, v)=(1,0) ; S(u, v)=\left(u^{2}+2,0\right) ; T(u, v)=(2,0) \text {, }
$$

for all $(\mathrm{u}, \mathrm{v}) \in \mathrm{X}$. Now, we find that $\mathrm{A}(\mathrm{X})=\mathrm{B}(\mathrm{X})=\mathrm{S}(\mathrm{X})=\mathrm{T}(\mathrm{X})=\mathrm{X}$, i.e., $\mathrm{A}, \mathrm{B}, \mathrm{S}$ and $\mathrm{T}$ are surjective mappings. Also A, B, S and T are sequentially continuous.

Assuming $\phi \in \Phi$ as $\phi(t)=\frac{1}{3} \mathrm{t}$ for each $\mathrm{t} \in[0, \infty)$, for any $\mathrm{x}, \mathrm{y} \in \mathrm{X}$, we have 


$$
\begin{aligned}
\phi(G(A x, B y, B z) & =\phi(G(A(u, v), B(s, t), B(p, q)) \\
& =\phi\left(G\left(\left(3 u^{4}+1,0\right),(1,0),(1,0)\right)=\phi\left(2\left(3 u^{4}\right)\right)\right. \\
& =2 u^{4} \geq 2 u^{2}=G(S x, T y, T z)
\end{aligned}
$$

Therefore, the condition (3.2) holds. So, all the hypotheses of Theorem 3.1 are satisfied except the compatibility of type (A) of the pair $\{\mathrm{A}, \mathrm{S}\}$ and $\{\mathrm{B}, \mathrm{T}\}$. Indeed, we see that

$$
\begin{aligned}
& \mathrm{G}\left(A x_{n}, S x_{n}, S x_{n}\right)=G\left(\left(\left(3 u_{n}^{4}+1,0\right),\left(u_{n}^{2}+2,0\right),\left(u_{n}^{2}+2,0\right)\right)\right. \\
& =2\left(3 u_{n}^{4}-u_{n}^{2}-1\right) \rightarrow 2 \text {, as } x_{n}\left(u_{n}, v_{n}\right) \rightarrow(1,0) . \\
& \mathrm{G}\left(\mathrm{ASx}_{\mathrm{n}}, \mathrm{SSx}_{\mathrm{n}}, \mathrm{SSx}_{\mathrm{n}}\right)=\mathrm{G}\left(\left(3\left(\mathrm{u}_{\mathrm{n}}^{2}+2\right)^{4}+1,0\right),\left(\left(\mathrm{u}_{\mathrm{n}}^{2}+2\right)^{2}+2,0\right),\left(\left(\mathrm{u}_{\mathrm{n}}^{2}+2\right)^{2}+2,0\right)\right) \\
& =2\left(3\left(u_{n}^{2}+2\right)^{4}-\left(u_{n}^{2}+2\right)^{2}-1\right) \rightarrow 466 \text {, as } x_{n}=\left(u_{n}, v_{n}\right) \rightarrow(1,0) . \\
& \mathrm{G}\left(\mathrm{SAx}_{\mathrm{n}}, \mathrm{AAx}_{\mathrm{n}}, \mathrm{AAx}_{\mathrm{n}}\right)=\mathrm{G}\left(\left(\left(3 \mathrm{u}_{\mathrm{n}}^{4}+1\right)^{2}+2,0\right),\left(3\left(3 \mathrm{u}_{\mathrm{n}}^{4}+1\right)^{4}+1,0\right),\left(3\left(3 \mathrm{u}_{\mathrm{n}}^{4}+1\right)^{4}+1,0\right)\right) \\
& =2\left(\left(3 u_{n}^{4}+1\right)^{2}+2-\left(3\left(3 u_{n}^{4}+1\right)^{4}\right)-1\right) \rightarrow-1502, \text { as } x_{n}=\left(u_{n}, v_{n}\right) \rightarrow(1,0) . \\
& \mathrm{G}\left(\mathrm{BTx}_{\mathrm{n}}, \operatorname{TTx}_{\mathrm{n}}, \operatorname{TTx}_{\mathrm{n}}\right)=\mathrm{G}((1,0),(2,0),(2,0)) \rightarrow 2, \mathrm{x}_{\mathrm{n}}\left(\mathrm{u}_{\mathrm{n}}, \mathrm{v}_{\mathrm{n}}\right) \rightarrow(1,0) . \\
& \mathrm{G}\left(\mathrm{TBx}_{\mathrm{n}}, \mathrm{BBx}_{\mathrm{n}}, \mathrm{BBx}_{\mathrm{n}}\right)=\mathrm{G}((2,0),(1,0),(1,0)) \rightarrow 2, \mathrm{x}_{\mathrm{n}}=\left(\mathrm{u}_{\mathrm{n}}, \mathrm{v}_{\mathrm{n}}\right) \rightarrow(1,0) .
\end{aligned}
$$

We give an application of theorem 3.1 to product space in the following way.

Corollary 3.2 Let $(\mathrm{X}, \mathrm{G})$ be a complete G-metric space. Consider the mappings A, B, S, and T: X $\times$ X $\rightarrow \mathrm{X}$ satisfying the following conditions;

(3.8) A and B are surjective,

(3.9) $\phi\left(G\left(A(x, y), B\left(x_{1}, y_{1}\right), B\left(x_{2}, y_{2}\right)\right) \geq G\left(S(x, y), T\left(x_{1}, y_{1}\right), T\left(x_{2}, y_{2}\right)\right)\right.$, for all $x, y, x_{1}, y_{1}, x_{2}$, and $\mathrm{y}_{2} \in \mathrm{X}$ and $\phi \in \Phi$,

(3.10) one of the mappings $\mathrm{A}, \mathrm{B}, \mathrm{S}, \mathrm{T}$ is sequentially continuous,

(3.11) the pair $\{\mathrm{A}, \mathrm{S}\}$ and $\{\mathrm{B}, \mathrm{T}\}$ are compatible mapping of type (A).

Then the mappings A, B, S and T have a unique common fixed point in X.

Proof - Since the pair $\{A, S\}$ and $\{B, T\}$ are compatible mapping of type (A), by definition, we have

$$
\begin{aligned}
& \lim _{n \rightarrow \infty} G\left(A\left(S\left(x_{n}, y\right), y\right), S\left(S\left(x_{n}, y\right), y\right), S\left(S\left(x_{n}, y\right), y\right)\right)=0 \text { and } \\
& \qquad \lim _{n \rightarrow \infty} G\left(S\left(A\left(x_{n}, y\right), y\right), A\left(A\left(x_{n}, y\right), y\right), A\left(A\left(x_{n}, y\right), y\right)\right)=0 \\
& \lim _{n \rightarrow \infty} G\left(B\left(T\left(x_{n}, y\right), y\right), T\left(T\left(x_{n}, y\right), y\right), T\left(T\left(x_{n}, y\right), y\right)\right)=0 \text { and }
\end{aligned}
$$




$$
\lim _{n \rightarrow \infty} G\left(T\left(B\left(x_{n}, y\right), y\right), B\left(B\left(x_{n}, y\right), y\right), B\left(B\left(x_{n}, y\right), y\right)\right)=0,
$$

whenever $\left\{x_{n}\right\}$ is a sequence in $X$ such that

$$
\lim _{n \rightarrow \infty} A\left(x_{n}, y\right)=\lim _{n \rightarrow \infty} B\left(x_{n}, y\right)=\lim _{n \rightarrow \infty} S\left(x_{n}, y\right)=\lim _{n \rightarrow \infty} T\left(x_{n}, y\right)=t .
$$

for some $t \in X$ and for every $y \in X$.

Now, from condition (3.9), we have

$$
\phi\left(G\left(A(x, y), B\left(x_{1}, y_{1}\right), B\left(x_{2}, y_{2}\right)\right) \geq\left(G\left(S(x, y), T\left(x_{1}, y_{1}\right), T\left(x_{2}, y_{2}\right)\right)\right.\right.
$$

for all $\mathrm{x}, \mathrm{y}, \mathrm{x}_{1}, \mathrm{y}_{1}, \mathrm{x}_{2}$, and $\mathrm{y}_{2} \in \mathrm{X}$.

From theorem 3.1, there exist a unique point $\mathrm{x}(\mathrm{y})$ in $\mathrm{X}$ such that

$$
\mathrm{x}(\mathrm{y})=\mathrm{A}(\mathrm{x}(\mathrm{y}), \mathrm{y})=\mathrm{B}(\mathrm{x}(\mathrm{y}), \mathrm{y})=\mathrm{S}(\mathrm{x}(\mathrm{y}), \mathrm{y})=\mathrm{T}(\mathrm{x}(\mathrm{y}), \mathrm{y}) \text { for each } \mathrm{y} \in \mathrm{X} \text {. }
$$

For uniqueness, let us consider $\mathrm{x}\left(\mathrm{y}_{1}\right)$ be different fixed point in $\mathrm{X}$, such that

$$
\mathrm{x}\left(\mathrm{y}_{1}\right)=\mathrm{A}\left(\mathrm{x}\left(\mathrm{y}_{1}\right), \mathrm{y}_{1}\right)=\mathrm{B}\left(\mathrm{x}\left(\mathrm{y}_{1}\right), \mathrm{y}_{1}\right)=\mathrm{S}\left(\mathrm{x}\left(\mathrm{y}_{1}\right), \mathrm{y}_{1}\right)=\mathrm{T}\left(\mathrm{x}\left(\mathrm{y}_{1}\right), \mathrm{y}_{1}\right)
$$

Suppose that $\phi\left(G\left(x(y), x\left(y_{1}\right), x\left(y_{1}\right)\right) \neq 0\right.$ for all $x\left(y_{1}\right)$ in $X$. Now, we obtain from (3.9) that, for each $y, y_{1}$ $\in \mathrm{X}$,

$$
\begin{aligned}
& \phi\left(G\left(x(y), x\left(y_{1}\right), x\left(y_{1}\right)\right)\right.=\phi\left(G\left(A(x(y), y), B\left(x\left(y_{1}\right), y_{1}\right), B\left(x\left(y_{1}\right), y_{1}\right)\right)\right. \\
& \geq G\left(S(x(y), y), T\left(x\left(y_{1}\right), y_{1}\right), T\left(x\left(y_{1}\right), y_{1}\right)\right)=G\left(x(y), x\left(y_{1}\right), x\left(y_{1}\right)\right)
\end{aligned}
$$

This contradiction leads to

$$
\phi\left(\mathrm{G}\left(\mathrm{x}(\mathrm{y}), \mathrm{x}\left(\mathrm{y}_{1}\right), \mathrm{x}\left(\mathrm{y}_{1}\right)\right)=0 \text { which implies } \mathrm{G}\left(\mathrm{x}(\mathrm{y}), \mathrm{x}\left(\mathrm{y}_{1}\right), \mathrm{x}\left(\mathrm{y}_{1}\right)\right)=0 \text {, i.e., } \mathrm{x}(\mathrm{y})=\mathrm{x}\left(\mathrm{y}_{1}\right)\right. \text {. }
$$

Hence, $\mathrm{x}($.$) is some constant, say, \mathrm{a} \in \mathrm{X}$ such that

$$
\mathrm{a}=\mathrm{A}(\mathrm{a}, \mathrm{y})=\mathrm{B}(\mathrm{a}, \mathrm{y})=\mathrm{S}(\mathrm{a}, \mathrm{y})=\mathrm{T}(\mathrm{a}, \mathrm{y}) \text { for each } \mathrm{y} \in \mathrm{X} \text {. }
$$

Hence A, B, S and T have a unique common fixed point $\mathrm{b}$ in $\mathrm{X}$.

Conclusion: Many applications of fixed point theorems and our main theorems are there, for instance game theory relevant to military, sports and medicine as well as boundary value problem, physics and economics [2]. In this paper, we prove a common fixed point theorem for expansive mapping in G-metric space in which we particularly stated application in product space.

\section{ACKNOWLEDGEMENTS}

The first author is gratefully acknowledged to Council of Scientific and Industrial Research, Government of India, for providing financial assistant under research project no- 25(0197)/11/EMR-II. 


\section{References}

[1] M. Abbas and B.E. Rhoades, Appl Math and Comput, 215,p261 (2009).

[2] K.C. Border, Fixed point theorem with application to economics and game theory, Cambridge University Press, (1990).

[3] B.C. Dhage, Bull. Calcutta Math Soc, 84,p329 (1992)..

[4] S.Gahler, Mathe Nachri, 26, p115(1963).

[5] C.R. Hsiao, Janabha, 16,p223 (1986).

[6] G.Jungck, Amer. Math. Monthly, 83, p261(1976).

[7] G.Jungck, Int. J. Math. Sc. 9, p771(1986).

[8] G.Jungck, P. P. Murthy and Y. J. Cho, Math. Japonica, 38,p381 (1993) .

[9] G.Jungck and B.E.Rhoades, Indian J. Pure Appl. Math., 29, p227(1998) .

[10] Z.Mustafa and B.Sims, Proceedings of International Conference on Fixed Point Theory and applications, Yokohama Publishers, Valencia Spain, July 13-19, p189(2004) .

[11] Z.Mustafa and B.Sims, A new approach to a generalized metric spaces, J. Nonlinear Convex Anal., 7,p289 (2006) .

[12] Z.Mustafa and H.Obiedat and F.Awawdeh, Fixed point theorey and applications, Volume 2008, Article ID189870(2008)

[13] Z.Mustafa, W. Shatanawi and M.Bataineh, International Journal of Mathematics and Mathematical Sciences, Volume 2009, Article ID. 283028,10 pages(2009).

[14] J. Murkowski, Proc. Amer Math, 62, p344(1977).

[15] R.P.Pant, J. Math.Anal. Appi, 188,p436 (1994).

[16] H.K. Pathak, Y. J. Cho, S. M. Kang and B. S. Lee, Lee. Mathematics, 50,p15 (1995) .

[17] Z. Peter Daffer and Hideaki Kaneko, Math. Japonic, 7, p733(1992) .

[18] S.Sessa, Publ. Inst. Math. Beograd, 32(46), p146(1982)

[19] S.Z. Wang, B.Y.Li, Z.M. Gao and K. Iseki, Math Japonic, 29, p631 (1984) . 